\title{
MARITAL AND FAMILY SATISFACTION ACCORDING TO THE COUPLE'S TYPE OF INTERPERSONAL RELATIONSHIPS
}

\author{
Natasha Virmozelova Angelova, Emelina Zaimova-Tsaneva \\ South-West University "Neofit Rilski", Bulgaria \\ E-mail: natasha.virmozelova@gmail.com, emelina_z@abv.bg
}

\begin{abstract}
The presented research was intended to explore the connection between the levels of marriage and family satisfaction with different interpersonal communication styles. The objective here was to find out whether the experienced level of marriage and family satisfaction will differentiate according to partner's interpersonal relationship style (authoritarian, egoistic, aggressive, suspicious, submissive, dependent, friendly and altruistic styles). A pilot study was conducted with one hundred participants comprised of males $(N=23 ; 23 \%)$ and females $(N=77 ; 77 \%)$ that completed three questionnaires made up of Leary`s (1957) scale that measured Interpersonal Relationships, Family Satisfaction by Adjectives Scale and Marital Satisfaction Questionnaire. Participants were within the age of 26 to 64 years $(M=43.6 ; S D=9)$. The obtained results pointed out that there were significant differences between examined persons with different interpersonal relationships upon their levels of family and marital satisfaction.
\end{abstract}

Keywords: intrapersonal relationships, family satisfaction, marital satisfaction.

\section{Introduction}

Interpersonal relationships represent communicational and behavioral acts, where the actions that are undertaken from the first side affect the other side in a given time (brief or enduring). People's behavior such as friendship, fellowship, or feelings as warmth and commitment between two or more people are the core of the interpersonal relationships (Clark \& Reis, 1988; Kelley, 1983). The closeness and friendship can be based on love, solidarity and support or just working together, and other types of social engagement. That is why the interpersonal relationships were split into two main categories (personal and professional). The first one could be divided into different types and these are as follows: friendship, romantic relation (intimate, love), and family relationship. To the second category belongs the professional (work) relationship with bosses, colleagues, clients, and patients, and of course all partners in the formal context, such as representatives of institutions.

Interpersonal relationships are formed through the active interaction and commitment with all other people in a social and cultural context where the influences are reciprocal. Interpersonal relationships are regulated in many different ways - by the law, by the social norms and customs, by mutual agreements, they are the root of society and serve as a basis to build it. By their mean- 
ing, interpersonal relationships are subjective personal attitudes of preference (or not preference), liking (disliking), sympathy (antipathy). A great deal of their nature is deeply emotional therefore they could not be objective and to approach them through a scientific point of view in some cases is also difficult.

Interpersonal relationships depend on the persons engaged in the interaction process and how aware of their own responsibility in this process the people are. Also, an important question here is how relevant the social roles are to the person who accomplishes them, how fulfilling is the emotional process that results from these interactions. The interpersonal relationships between people are constantly and gradually developing, so that researching all these questions shapes and influences the mutual understanding of the existence of social relationships and social roles and especially when speaking about the conception of interpersonal relations in social psychology and moreover in the psychology of family.

The accent of the prior studies in the area of interpersonal relationships was on the attraction process that occurred between people, rather than on the interpersonal relationships itself (Burgess \& Cottrell, 1939). Later the researchers focused on the social context and emotional phenomenon that was observed in a real and occurring relationship (Johnson, 1991; Kelley, 1983).

New directions in interpersonal relationship perspective have been taken by House, Landis, and Umberson (2003). Their research perspective demonstrated that the quality of interpersonal relations had an effect on physical and mental health. When people lack warm and meaningful relationships with other people, their health suffers much more than do people with satisfied interpersonal relationships.

The real quality of the relationship is seen in the communication process. Communication plays a crucial role to understand many difficult situations and tensions between people. The communication process gives the opportunity to contact, attach to the others and express oneself. The process is dynamic and also refers to people's skill to articulate their interpersonal relationship needs. This perspective takes into account the accent on the dyad (couple) instead of on the individual (Couch, 1992; Duck, 1990). The optimal communication is observed as healthy and as a key to a long lasting relationship when individuals do express and reciprocate their emotions, feelings, thoughts. To have immediate contact makes it possible to experience interpersonal relationship satisfaction. Without a direct contact it is impossible to have such kind of relationships.

On another hand, when speaking about marriage or sort of intimate relationships, any person who begins its romantic relationship has its own individual system of beliefs, needs, which is a prerequisite for joint life. Personality seeks to satisfy these needs in conjoint actions as mating, building a family, giving birth to children, etc.

Interpersonal communication in the family is an important factor for its optimal functioning. In this sense, the social competence of the individuals, the frequency of interpersonal contacts and intragroup consistency are important for the family spirit. Non-verbal and verbal communication in the family depends on the development of empathy, self-presentation, self-control, skills to overcome crisis situations, and tackle the issues of a different nature (sickness, stress, aging, etc.).

Family relationships are seen as a complex or dynamic system where different personalities have a huge amount of variety of interactions with each other (Skinner, Steinhauer \& Sitarenios, 2000). The basic idea of the family system 's theories is based on the ability of family members to adapt to each other and react, according to the family rules and hierarchy (Świętochowski, 2010). The experienced satisfaction serves a proof of the stability of the family unit. A well-functioning family has family members with high satisfaction in interpersonal relationships.

The quality of family life has high personal and social value. It is associated with the stability of the structure; harmonious development and functioning; a place where people evaluate their mates and experience love and appreciation.

As a social group, the family satisfies human 's specific needs for personal and social relationships. Interpersonal relations and communication in the family are characterized by a particular emotional intensity and through this emotional interaction are transmitted significant social values, norms, habits, patterns of behavior between the generations (Yakova, 2016). 
In a general sense, family satisfaction is a state in which our intimate and important desires are satisfied and personal needs are met. It is a subjective feeling of a pleasant experience; it is also the result of social, emotional and psychological interaction between people in a close relationship, especially between lovers, spouses, partners, parents, children and extended family (Akhlaq, Malik, \& Khan, 2013).

Family satisfaction depends to a large extent on the reconciliation of the individuals with the common interests in building a strong family relationship (Olson \& DeFrain, 2000). From a personal point of view, family satisfaction is the balance between dreams and desires, on one hand, and on the other - their realization. So, when people feeling their personal wishes are met by the mate and also they can take care of the partner's needs, could be said they are satisfied with their relationship.

According to Ritzer (2011), people's desires are an important psychic component of the personality structure, and therefore the satisfaction is an inner state. Veenhoven (1996) defined family satisfaction as a subjective assessment of the quality of the relationship and believed that this satisfaction depended on two factors: the perception or subjective understanding of the relationship, and the outcome of the relationship itself. The positive outcome is not a sufficient factor for family satisfaction. If the subjective evaluation of the relationship is negative for one of the partners, the satisfaction for both will be down.

There are different approaches to analyzing family satisfaction. Brazelton and Yogman (1986) noted that family satisfaction was achieved by the existence of satisfaction among spouses as a result of the harmony levels between them, concerning the way of managing family life. How much time they spend on housework, what kind of relationship they have with each other, and how they express their emotions, are the points of Brazelton and Yogman`s (1986) research.

The understanding of the cognitive approach is based on the fact that each partner has a set of beliefs about the empathic connection that is wanted to be available in an intimate relationship (Friedberg, 2006). The perception of the partner's behavior is much more important than the behavior itself. People's belief that their ideas and conclusions about life are realistic, give them the strength and motivation to explore them in real situations. Since interpersonal relationships in the family are concerned, this approach focuses on how couples interpret each other's behavior and then evaluate the partner's conviction by comparing it with its own ideas and approaches of solving problems (Beck, 1995).

According to the cognitive approach, in order to achieve satisfaction, couples need to be able to create an emotional relationship with each other, to get used to solving their problems by mutual consent, to create conditions for reducing tensions in interpersonal relationships, to learn to express their emotions and desires, to find out how to improve their sexual relationship, to learn about achieving self-confidence in their behavior (Dattilio, 2001).

The degree of marital satisfaction of the spouses depends on a number of conditions that ensure the functioning of the relationships within the family so that partners can be satisfied with each other.

Summarizing the literature (Akhlaq, Malik, \& Khan, 2013; Brazelton \& Yogman, 1986; House, Landis, \& Umberson, 2003; Olson \& DeFrain, 2000; Skinner, Steinhauer, \& Sitarenios, 2000) were distinguished nine factors of great importance for family satisfaction. Those were combined into four categories as follows:

1. Strength - Power, Financial stability;

2. Behavior - Spending free time, Support in stressful situations

3. Conceptualization - Life conceptions and values, Expectations

4. Personality - Personal characteristics, Compatibility, Interpersonal relationships, Some of these conditions have a particular meaning: 
Power in the family

One of the most significant conditions influencing both positive and negative intimate relationships is how couples distribute power among themselves. The explanatory model for the distribution of power in the family can be best explained by Mead's (1997) theory of social interaction and more specifically, through the theory of social roles (Eagly \& Wood, 2012). According to the theory of social roles, one refuses from those behavioral patterns that are not appreciated by the partner. People shape themselves, according to the partners ' needs. The roles they take in time become part of their personality. According to Stamatov, and Minchev (2003), personality is what the ego reflects in other people's mind. Women and men accept their roles in a different way and most often they are determined by the requirements of the social environment. In family life, conflicts are inevitable, but in order to reduce their risk, partners are required not only to integrate with one another but also to assimilate each other. This does not mean partners are about to lose their personality - but to try to harmonize and complement each other. Empathy and understanding facilitate communication between them. The emphasis of this theory is on the understanding of each individual about the situation and behavior of the partner, and only by respecting this understanding couple's conflicts could be comprehended (Moskowitz, Suh, \& Desaulniers, 1994).

Financial stability of the family.

Regardless of whether the family is financially secured or not, spending money often creates unpleasant discussions between couples. Misunderstandings, when distributing the financial resources or taking decisions by only one of the partners very often, leads to conflict. Conflict can also arise when one receives more income and tries to control the spending of the other counterpart. Often, men with high incomes have to spend too much time at their workplace instead of being home with their family. This can become an obstacle to a happy and satisfied family life. Family life is based on the use of the terms "ours" and "this is our problem". Partners work together to find a solution on how to manage their financial resources, so that to boost family satisfaction and to avoid any misunderstandings between them.

\section{Behavior}

Support in stressful situations

Over the years of family life, one or more family members have problems that need to be resolved. Solving these problems requires the mutual adjustment of family members. An inability or lack of desire in this direction leads to a conflict in the couple's relationship. The lost of intimacy, financial crisis, child-raising problems, chronic illnesses are an only small part of the possible stressful situations. Such events may include depression, mental illness, and disability of a family member, retirement, children problems, pregnancy, and alcoholism. Satisfaction with the intimate partner when some of the listed moments occur requires strong support, assistance, and understanding. The satisfaction with the partner and quality of the couple's relationship are very important for both physical and mental health.

Spending free time

The way couples spend their free time is different and depends on many factors such as past experiences, financial opportunities, interests, and leisure. Nowadays, modernizations, industrialization, new forms of communication lead to a tendency for alienation between members of society and family. Modern people have a lot of responsibilities and usually are multitasking. They can hardly cope with the stress and the lack of time but a good plan about family duties and chores at least helps couples to avoid conflicts and have more time to spend doing together some leisure 
activities. To have free time and good mental predisposition to enjoy family life requires sometimes

too much energy and for sure to allow oneself to relax with the beloved one and family as a whole.

\section{Conceptualization}

\section{Expectations}

Having great expectations leads to a boring life, irritation, emotional tension, and when partners stuck in a situation like that they do not feel happy and satisfied in their relationship. When partners go along together and do not have unrealistic expectations, they undertake actions that help to rebuild the connection between them and thus increases the family satisfaction. According to Stamatov, and Minchev (2003), the knowledge we have for other people depends on our own experience as well. The knowledge we have about our own experience helps to understand the experience of others, it is a result also from people's interests, experienced emotions, needs and beliefs about the partner's world.

Life conceptions and values

Within the family, similar life conceptions and mutual values are conditions for satisfaction. If partners stand on different viewpoints, if they do not have close comprehension about the life issues and how to tackle them, they are dissatisfied with the marriage and family. Similar life convictions and way of thinking are important to the relationship between the couple. Based on these is the philosophy of life of each of them. In order to develop and achieve a trustful relationship, there is a need for some stability and predictability of the partner's perspective. Even if this trustful relationship is not well built, at least it should be available. And this is truly important when speaking about children who need the most sustainable context where to grow up. In marital relationship everyone gains experience but also enters this field with one's own heritage of the family of origin, that is, the expectations for the future start from the past.

\section{Personality}

\section{Personal characteristics}

The personal experience from the childhood period and the family of origin are related to the further ability to establish relationships in society. The family has rules and principles that are formed on the basis of common interests, representations and beliefs of family members. The existence of emotional attachment among family members gives children traditions, behavioral patterns, values, and worldview. Relationships in the family of origin influence the building of some personal characteristics, skills, and behavioral patterns. When raising children, the most important thing is to grow them in a secure and warm atmosphere where prevail cohesiveness, identity, empathy, independence.

An important personality characteristic for family satisfaction is the willingness to cooperate with the family partner. It is defined as the degree of the desire of the partners to listen to each other's requirements and to help solve emerging family problems (Schrodt, 2009). It is common for the mates to have different views and insist on them. When their conceptions are reasonable, well articulated and with respect to the other's needs, spouses can, through cooperation and careful communication, solve their problems, such as child education, management of the family budget, planning holidays. It rarely happens when one of the spouses is not satisfied with the situation or the behavioral patterns acted in the relationship, to have a penetrating mind and to find a suitable moment and constructive way to discuss the problem with the partner. Therefore, one of the most desirable personal characteristics concerning interpersonal relationship is the sense of cooperation. A satisfying sense of cooperation and communication with the other gives the energy to the individual to act, develop and to strive for a bright perspective in the relationship with the mate. 
Building interpersonal relationship is a process of transmitting and exchanging thoughts, feelings and opinions between connected people. For this purpose, they use appropriate characters to influence or control the other person. They exchange messages to reach a common understanding. In intimate interpersonal relationships, one may have the possibility to participate in a shared emotional context. When couples share honest and sincere interpersonal contact, they can express their negative emotions appropriately in a safe and tolerant environment. Partner's requirements have a strong effect on family development. If one of the mates brings an unrealistic expectation to the other partner or the family, it costs many troubles. Conversely, if the requirements match the real qualities and abilities of the mates, then the risk of conflict shrinks sharply (Krastev \& Yordanova, 2017).

\section{Compatibility between partners}

The compatibility is one of the most important conditions for family satisfaction (Obozov, 1990). There are different types of compatibility: character, emotional, genetic, sexual, social, ethnical, and religious. Sexual compatibility is one of the specific fields that may attract interest in many people but it is not only one that occupies people's mind. Satir (2001) wrote in relation to psychological compatibility that people who marry very often do not know themselves in essence. Sexual attraction may prompt them to bond their destinies, but it does guarantee neither character compatibility nor friendship. Compatibility is defined as the mutual acceptance of partners based on optimal matching or similarity of value orientations, personal and psycho-physiological features (Kessler, 2015; Van Lange et al., 1997). When explaining or describing family relationships, a reach diversity of psychological factors and components is used. For decades psychologists have been engaged in studying the compatibility of marriage, friendship, and work (Gaughan, 1995; Georgiou, 1995; Gohm et al., 1998). As a result, it has been found that most successful family couples with reliable relationship have rather opposite temperaments. The interaction between the mates should be reciprocal and balanced, their personalities should complement each other in order to participate in the partnership (Weissman, Markowitz, \& Klerman, 2000).

\section{Aim}

This was a pilot study that was done to reveal the differences between family and marital satisfaction in adults regarding their types of interpersonal relationships. There were taken into account also some social-demographic factors such as marital status and gender.

\section{Hypothesis}

$\mathrm{H}_{1}$ : It was suggested that there were significant differences between the experienced levels of marriage and family satisfaction according to the different interpersonal relationships.

$\mathrm{H}_{2}$ : It was assumed that there would be found rank correlations between the levels of marital satisfaction and some interpersonal relationships, and between the degrees of family satisfaction and some interpersonal relationships.

\section{Research Methodology}

\section{General Background}

The research was carried out in the period: 01.04.2018 - 31.05.2018 in the territory of the Republic of Bulgaria. Every participant was approached through an interviewer and was allowed to have a look at questionnaires in order to make a decision about participating in the survey. To 
guarantee the confidentiality of the research, participants were told the study is anonymous and

they filled in a consent declaration. The research instruments were handed to every individual who could choose to fill them out at that very moment or at home and return them back within 5 days. There was a detailed instruction on each instrument

\section{Participants}

Since this was a pilot examination it was conducted with 100 individuals aged between 26 to 64 years $(M=43.6, S D=9) .77(77 \%)$ females and $23(23 \%)$ males took part in the research. 91 (91\%) were married and only $9(9 \%)$ lived in cohabitation. They were assured that their personal data would not be used for other purposes. Convenience sampling was used.

\section{Research Instruments}

Family Satisfaction by Adjectives Scale (FSAS) by Barraca, Yarto, and Olea (2000) - adapted by Bulgarian conditions by Angelova and Zaimova-Tzaneva (2018).

F.S.A.S is a one-dimensional scale containing 27 items constructed in 14 adjective pairs measuring family satisfaction. The tool starts with the sentence "When I'm at home, with my family, I mostly feel .... Adjective pairs follow this sentence. Using the word "at home" is to emphasize the most natural environment of family relationships. The investigated person responded to each item by pointing out an adjective of the couple that most closely matched his or her personal feelings and determined his degree of expression with the alternatives - "totally", "quite", "to some extent".

Questionnaire for measuring marital satisfaction (Stolin, Romanova, \& Buttenko, 1984).

It is designed to diagnose the degree of satisfaction with the marriage. The method is a onedimensional scale, consisting of 24 statements related to different areas: perception of self and partner, opinion, assessment, attitude, etc. There are 3 options for answering each statement. When developing the questionnaire, the authors suggest that the subjective satisfaction/dissatisfaction with marriage by nature is rather a generalized emotion, a summarized experience than a consequence of a rational assessment (Stolin, Romanova, \& Buttenko, 1984).

Method for Interpersonal Relationship Diagnostics (by Timothy Leary). This methodology is designed to explore the style, the nature and the structure of interpersonal relationships, and hence their behavioral characteristics (Petrova, 2016). Leary's test allows outlining 16 interpersonal relationships types build on 8 basic sorts of personal characteristics. The questionnaire itself consists of 128 simple statements, which are grouped into eight scales (the author calls them "octants") and every scale consists of 16 items. It is used very often to study the self-esteem and the level of selfsatisfaction and expectations in interpersonal relationships (Leary, 1957).

\section{Procedure and Measures}

The statistical package SPSS 16 was used and the undertaken analyzes were:

- T-test - statistical criterion for studying independent samples (Jonev, 2005);

- Pearson's chi-square test - a nonparametric hypothesis verification method serving to evaluate the relationship between variables of category (nominal and ordinate) scales (Stoyanova, 2007);

- Kruskal-Wallis test is a nonparametric criterion for comparing equal or different sample sizes. It was used for comparison of 2 or more groups of different participants in each group. Kruskal-Wallis test gives a chi-squared. However, its degree of freedom is more than 1, and thus it is not straightforward to convert the chi-squared into the effect size (Field, 2013).

Spearman 's rank correlation coefficient or Spearman's rho is a nonparametric measure of rank correlation (statistical dependence between the ranks of two variables (Wayne, 1990). 


\section{Research Results}

\section{Overall Results}

The conducted statistical analysis given in Table 1 demonstrated the distribution of the researched sample regarding the levels of the three factors: types of interpersonal relationships, marital and family satisfaction.

Table 1. Distribution of the results on the researched variables by different levels (low, middle, high), number and percent of the participants, $\mathbf{N}=100$.

\begin{tabular}{|c|c|c|}
\hline Variables & $\begin{array}{c}\text { Levels } \\
\text { 1-low 2-middle 3-high }\end{array}$ & $n / \%$ \\
\hline & 1 & 3 \\
\hline \multirow{2}{*}{ Family satisfaction } & 2 & 82 \\
\hline & 3 & 15 \\
\hline Total & & 100 \\
\hline \multirow{3}{*}{ Marital satisfaction } & 1 & 12 \\
\hline & 2 & 76 \\
\hline & 3 & 12 \\
\hline Total & & 100 \\
\hline \multirow{3}{*}{ Authoritarian } & 1 & 56 \\
\hline & 2 & 32 \\
\hline & 3 & 12 \\
\hline Total & & 100 \\
\hline \multirow{3}{*}{ Aggressive } & 1 & 59 \\
\hline & 2 & 37 \\
\hline & 3 & 4 \\
\hline Total & & 100 \\
\hline \multirow{3}{*}{ Suspicious } & 1 & 83 \\
\hline & 2 & 14 \\
\hline & 3 & 3 \\
\hline Total & & 100 \\
\hline \multirow{3}{*}{ Obedient } & 1 & 55 \\
\hline & 2 & 28 \\
\hline & 3 & 17 \\
\hline Total & & 100 \\
\hline \multirow{3}{*}{ Selfish } & 1 & 58 \\
\hline & 2 & 39 \\
\hline & 3 & 3 \\
\hline Total & & 100 \\
\hline \multirow{3}{*}{ Dependent } & 1 & 50 \\
\hline & 2 & 39 \\
\hline & 3 & 11 \\
\hline Total & & 100 \\
\hline
\end{tabular}




\begin{tabular}{|c|c|c|}
\hline Variables & $\begin{array}{c}\text { Levels } \\
\text { 1-low 2-middle 3-high }\end{array}$ & $n \mid \%$ \\
\hline & 1 & 27 \\
\hline \multirow[t]{2}{*}{ Friendly } & 2 & 37 \\
\hline & 3 & 30 \\
\hline Total & & 100 \\
\hline \multirow{3}{*}{ Altruistic } & 1 & 33 \\
\hline & 2 & 34 \\
\hline & 3 & 27 \\
\hline Total & & 100 \\
\hline
\end{tabular}

The results from Table 1 made it clear that $82 \%$ of the Bulgarian sample showed an average degree of family satisfaction, $15 \%$ of people from the given sample were highly satisfied with their family, and only $3 \%$ had low family satisfaction. At the same time, $12 \%$ of the participants reported low levels of marital satisfaction, and $12 \%$ also had a high degree of marital satisfaction, the rest of the people with a middle degree on marital satisfaction were $76 \%$ of the sample. It makes an impression that there is a difference between the percent of people having low levels on marital satisfaction (12\%) and these that showed low family satisfaction (3\%). These results seem to be very optimistic regarding the number of people with low levels of family and marital satisfaction, and they give some information that these two questionnaires (about family satisfaction and marital satisfaction) measured in some extent different concepts. First one gave information about the feelings with the partner and the second one is about the satisfaction with the whole family, but not only the mate. In this sample, the most common type of interpersonal relationships regarding the high levels was the friendly type with $30 \%$ of frequency and the altruistic with $27 \%$. With the lowest frequency in regard to the high levels were the selfish type with $3 \%$ representation in this sample, and suspicious with also $3 \%$ of frequency.

Having analyzed the data with $\mathrm{t}$-test, the results showed there were no significant differences in this sample between married persons and those who lived in cohabitation by the levels of their marriage $t(98)=0.888, p=.377$ and family satisfaction $t(98)=0.729, p=.468$.

Table 2. I-test analysis for independent samples showing the differences in marital and family satisfaction by married and cohabitating participants, $N=100$.

\begin{tabular}{cccccccc}
\hline Variables & Marital status & $\boldsymbol{N}$ & $\boldsymbol{M}$ & $\boldsymbol{S D}$ & $\boldsymbol{t}$ & $\boldsymbol{d}$ & $\boldsymbol{p}$ \\
\hline Marital & Married & 91 & 37.14 & 6.074 & \multirow{2}{*}{0.888} & & \multirow{2}{*}{.377} \\
satisfaction & In cohabitation & 9 & 35.11 & 10.505 & & \multirow{2}{*}{98} & \\
\cline { 1 - 5 } Family & Married & 91 & 141.29 & 14.128 & \multirow{2}{*}{0.729} & & .468 \\
satisfaction & In cohabitation & 9 & 137.56 & 19.500 & & & \\
\hline
\end{tabular}

When examining the differences in the gender sampling the used $T$-test showed lack of statistically significant differences between males and females by the levels of their marriage $t(98)=$ $0.142, p=.888$ and family $t(98)=0.880, p=.381$ satisfaction.

Taking into account the limitation of the study about its lack of equality of the gender sampling it is hardly to be said that the gender is a prerequisite for a different way of experiencing marriage and family satisfaction, but it still remains a variable that is interesting to be explored in relation to marital and family satisfaction. 
Table 3. $\quad t$-test analysis for independent samples showing the differences in marital and family satisfaction by male and female participants, $\mathbf{N}=\mathbf{1 0 0}$.

\begin{tabular}{cccccccc}
\hline Factors & Gender & $\boldsymbol{N}$ & $\boldsymbol{M}$ & $\boldsymbol{S D}$ & $\boldsymbol{t}$ & $\boldsymbol{d}$ & $\boldsymbol{p}$ \\
\hline Marital & Male & 23 & 37.13 & 6.05 & \multirow{2}{*}{0.142} & & \multirow{2}{*}{.888} \\
satisfaction & Female & 77 & 36.90 & 6.71 & & \multirow{2}{*}{98} & \\
\cline { 1 - 6 } Family & Male & 23 & 143.30 & 12.85 & \multirow{2}{*}{0.880} & & \multirow{2}{*}{.381} \\
satisfaction & Female & 77 & 140.25 & 15.09 & & & \\
\hline
\end{tabular}

In order to gain a better understanding and detect differences, a chi-square analysis was performed to compare the types of interpersonal relationships by the degrees of family satisfaction.

From the Table 4, in the middle level of family satisfaction could be seen that the most frequent type of interpersonal relationships was the friendly style (37\%), followed by the altruistic type of interpersonal relationships with $34 \%$.

Table 4. Comparison between the different levels of interpersonal relationships upon the levels of family satisfaction, chi-square value $\left(X^{2}\right)$, coefficient of significance $(p)$, number and percent of the participants, $N=100$.

\begin{tabular}{|c|c|c|c|c|}
\hline \multirow{2}{*}{ Interpersonal relationship } & \multicolumn{3}{|c|}{ Levels of Family satisfaction } & \multirow{2}{*}{$N / \%$} \\
\hline & Low & Middle & High & \\
\hline \multicolumn{5}{|l|}{ Authoritarian } \\
\hline Low & 3 & 47 & 6 & 56 \\
\hline Middle & 0 & 29 & 3 & 32 \\
\hline High & 0 & 6 & 6 & 12 \\
\hline Total & 3 & 82 & 15 & 100 \\
\hline \multicolumn{5}{|l|}{$\chi^{2}(4, N=100)=15.332 ; p=.004$} \\
\hline \multicolumn{5}{|l|}{ Aggressive } \\
\hline Low & 0 & 54 & 5 & 59 \\
\hline Middle & 2 & 27 & 8 & 37 \\
\hline High & 1 & 1 & 2 & 4 \\
\hline Total & 3 & 82 & 15 & 100 \\
\hline \multicolumn{5}{|l|}{$\chi^{2}(4, N=100)=17.565 ; p=.002$} \\
\hline \multicolumn{5}{|l|}{ Suspicious } \\
\hline Low & 1 & 72 & 10 & 83 \\
\hline Middle & 1 & 9 & 4 & 14 \\
\hline High & 1 & 1 & 1 & 3 \\
\hline Total & 3 & 82 & 15 & 100 \\
\hline \multicolumn{5}{|l|}{$\chi^{2}(4, N=100)=15.397 ; p=.004$} \\
\hline \multicolumn{5}{|l|}{ Obedient } \\
\hline Low & 2 & 43 & 5 & 50 \\
\hline Middle & 0 & 32 & 7 & 39 \\
\hline High & 1 & 7 & 3 & 11 \\
\hline Total & 3 & 82 & 15 & 100 \\
\hline
\end{tabular}




\begin{tabular}{|c|c|c|c|c|}
\hline \multirow{2}{*}{ Interpersonal relationship } & \multicolumn{3}{|c|}{ Levels of Family satisfaction } & \multirow{2}{*}{$\mathrm{N} / \%$} \\
\hline & Low & Middle & High & \\
\hline \multicolumn{5}{|l|}{ Selfish } \\
\hline Low & 1 & 51 & 6 & 58 \\
\hline Middle & 2 & 29 & 8 & 39 \\
\hline High & 0 & 2 & 1 & 3 \\
\hline Total & 3 & 82 & 15 & 100 \\
\hline \multicolumn{5}{|l|}{$\chi^{2}(4, N=100)=3.906 ; p=.419$} \\
\hline \multicolumn{5}{|l|}{ Dependant } \\
\hline Low & 2 & 49 & 4 & 55 \\
\hline Middle & 0 & 22 & 6 & 28 \\
\hline High & 1 & 11 & 5 & 17 \\
\hline Total & 3 & 82 & 15 & 100 \\
\hline \multicolumn{5}{|l|}{$\chi^{2}(4, N=100)=7.697 ; p=.103$} \\
\hline \multicolumn{5}{|l|}{ Friendly } \\
\hline Low & 2 & 24 & 1 & 27 \\
\hline Middle & 1 & 31 & 5 & 37 \\
\hline High & 0 & 27 & 9 & 36 \\
\hline Total & 3 & 82 & 15 & 100 \\
\hline \multicolumn{5}{|l|}{$\chi^{2}(4, N=100)=7.976 ; p=.092$} \\
\hline \multicolumn{5}{|l|}{ Altruistic } \\
\hline Low & 2 & 30 & 1 & 33 \\
\hline Middle & 1 & 28 & 5 & 34 \\
\hline High & 0 & 24 & 9 & 33 \\
\hline Total & 3 & 82 & 15 & 100 \\
\hline
\end{tabular}

The interactions that demonstrated statistically significant results, shown in the previous table, were between the levels of authoritarian type and the degrees of family satisfaction; between the levels of aggressive type and the degrees of family satisfaction; the levels of suspicious type and the degrees of family satisfaction.

The result obtained for the authoritarian type was $\chi^{2}(4, N=100)=15.335 ; p=.004$ and demonstrated that there were statistically significant differences between this type of interpersonal relationship and the degree of family satisfaction. There were $12 \%$ of the participants with an authoritative type of interpersonal relationships and $6 \%$ of them had a middle degree of family satisfaction. From the same group of people there were $6 \%$ of people who reported a high level of authoritative type interpersonal relationships and at the same time experienced a high level of family satisfaction that is to say wanted to dominate and relied in their partnership on an authoritarian style.

There were found statistically significant differences also between people that correspond to the aggressive type of interpersonal relationships upon the degree of family satisfaction $\chi^{2}(4, N=$ $100)=17.565 ; p=.002$. Most of the people in this group demonstrated low degree in aggressive type interpersonal relationships, from all $4 \%$ of participants with a high degree of aggressive type $2 \%$ showed a high level of family satisfaction.

There were presented statistically significant differences between the level of suspiciousness and the degree of family satisfaction $\chi^{2}(4, N=100)=15.397 ; p=.004$. From all $15 \%$ persons with 
high family satisfaction only $1 \%$ showed high level on suspiciousness, $4 \%$ with middle and $10 \%$ with low degree of family satisfaction.

There were no statistically significant differences between the level of obedient type relationships and the degree of family satisfaction $\chi^{2}(4, N=100)=5.411 ; p=.248$. From all $11 \%$ with an obedient type of interpersonal relationship 3\% showed a high degree of satisfaction and behaved as subordinate. Referring to the differences between the selfish type and family satisfaction the results are not statistically significant $\chi^{2}(4, N=100)=3.906 ; p=.419 .3 \%$ of responding persons had a high level of selfish type of interpersonal relationships and $1 \%$ pointed out a high degree of family satisfaction. The other results without statistical significance were between the level of dependant type relationship and family satisfaction. And there were $17 \%$ of the participants, who had high levels of the dependent type of interpersonal relationship and 5\% of them, showed a high degree of family satisfaction $\chi^{2}(4, N=100)=7.697 ; p=.103$. Overall, from all people with a high degree on interpersonal relationships, there were $36 \%$ of all participants that demonstrated a friendly type of interpersonal relationship and only $9 \%$ of them had a high degree of family satisfaction $\chi^{2}(4, N=100)=7.976 ; p=.092$. From all surveyed people $33 \%$ had an altruistic type of interpersonal relationships and $9 \%$ of them showed a high degree of family satisfaction $\chi^{2}(4, N=100)=9.154 ; p=.057$.

A Kruskal-Wallis analysis gave us only two chi-squared results from all eight (8) interactions that had statistically significant differences (Table 5). This analysis was done to differentiate more clearly the distinctions between the levels of experienced marriage satisfaction according to the type of interpersonal relationship. So, the results found for supporting the hypothesis were between the suspicious type of interpersonal relationships and the level of marital satisfaction with $\chi^{2}(2, N=100)=7.668 ; p=.022$. The obtained result demonstrated significant differences between people with a suspicious type of relationship and the degree of marital satisfaction. It was also presented statistically significant results between the "dependant" type of interpersonal relationships and experienced levels of marriage satisfaction $\chi^{2}(2, N=100)=9.592 ; p=.008$.

Table 5. Kruskal-Wallis analysis (measured by chi-square) showing the interaction between the type and level of interpersonal relationships and the degree of satisfaction with the marriage, coefficient of significance $(p)$, percent and mean rank, $N=100$.

\begin{tabular}{lccc}
\hline Types of interpersonal relationship & $\begin{array}{c}\text { Levels of marital } \\
\text { satisfaction } \\
\text { 1-low 2-middlle } \\
\text { 3-high }\end{array}$ & $\%$ & Mean Rank \\
\hline Authoritarian & 1 & 12 & 52,33 \\
& 2 & 76 & 49,92 \\
$\chi^{2}(2, \mathrm{~N}=100)=0.160, p=.923$ & 3 & 12 & 52,33 \\
\hline Aggressive & 1 & 12 & 55,71 \\
& 2 & 76 & 50,39 \\
\hline$\chi^{2}(2, \mathrm{~N}=100)=0.909, \mathrm{p}=.635$ & 3 & 12 & 46,00 \\
\hline \multirow{2}{*}{ Suspicious } & 1 & 12 & 62,92 \\
& 2 & 76 & 49,88 \\
\hline$\chi^{2}(2, \mathrm{~N}=100)=7.668, p=.022$ & 3 & 12 & 42,00 \\
\hline
\end{tabular}




\begin{tabular}{|c|c|c|c|}
\hline Types of interpersonal relationship & $\begin{array}{l}\text { Levels of marital } \\
\text { satisfaction } \\
\text { 1-low 2-middlle } \\
\text { 3-high }\end{array}$ & $\%$ & Mean Rank \\
\hline \multirow{3}{*}{ Obedient } & 1 & 12 & 63,17 \\
\hline & 2 & 76 & 49,32 \\
\hline & 3 & 12 & 45,29 \\
\hline \multicolumn{4}{|l|}{$\chi^{2}(2, N=100)=3.470, p=.176$} \\
\hline \multirow{3}{*}{ Selfish } & 1 & 12 & 49,71 \\
\hline & 2 & 76 & 50,75 \\
\hline & 3 & 12 & 49,71 \\
\hline \multicolumn{4}{|l|}{$\chi^{2}(2, N=100)=0.032, p=.984$} \\
\hline \multirow{3}{*}{ Dependent } & 1 & 12 & 70,46 \\
\hline & 2 & 76 & 49,21 \\
\hline & 3 & 12 & 38,71 \\
\hline \multicolumn{4}{|l|}{$\chi^{2}(2, N=100)=9.592, p=.008$} \\
\hline \multirow{3}{*}{ Friendly } & 1 & 12 & 64,25 \\
\hline & 2 & 76 & 48,54 \\
\hline & 3 & 12 & 49,17 \\
\hline \multicolumn{4}{|l|}{$\chi^{2}(2, N=100)=3.399, p=.183$} \\
\hline \multirow{3}{*}{ Altruistic } & 1 & 12 & 64,33 \\
\hline & 2 & 76 & 48,47 \\
\hline & 3 & 12 & 49,50 \\
\hline
\end{tabular}

$\chi^{2}(2, \mathrm{~N}=100)=3.440, \mathrm{p}=.179$

There were no statistically significant differences between aggressive type of interpersonal relationships and the level of marriage satisfaction $\chi^{2}(2, N=100)=0.909 ; p=.635$; between the selfish type of interpersonal relationship and the level of marital satisfaction $\chi^{2}(2, N=100)=0.032$; $p=.984$. In regard to the authoritarian type of relationship there were no significant results in the degree of manifestation of this type due to the marriage satisfaction $\chi^{2}(1, N=100)=0.160 ; p=$ .923; there was no demonstrated significant result on the obedient type of interpersonal relationship according to the level of satisfaction with the mate $\chi^{2}(2, N=100)=3.470 ; p=.176$. Also, there were no statistically significant results in the experienced level of marital satisfaction and the friendly type of interpersonal relationship $\chi^{2}(2, N=100)=3.399 ; p=.183$. There were no statistically significant results in the degree of marital satisfaction and altruism as a type of interpersonal relationship $\chi^{2}(2, N=100)=3.440 ; p=.179$.

So, regarding the first hypothesis should be said that it was proved. Although, there were no statistically significant differences between some factors it could be said with some certainty that the first suggestion was proven, namely the obtained results pointed out that people with different interpersonal relationships differentiate by the degree of marriage and family satisfaction.

To get the results clear and to prove the second hypothesis was performed a Spearman correlation analysis that supported the outcomes from the previous two statistical procedures (Chi-square and Kruskal-Wallis). The main reason to use correlation analysis was the research interest about the way in which the evaluated variables influenced each other or to say it with other words to explore the statistical dependence between the experienced levels of marital and family satisfaction, and the manifestation of different types of interpersonal relationships. 
OF PSYCHOLOGY

IN THE $21^{\text {st }}$ CENTURY

Vol. 13, No. 1, 2019

Table 6. Correlation analysis (Spearman`s rho) showing the relation between the levels of interpersonal relationships and the degree of satisfaction with the marriage and family, coefficient of significance (p), $N=100$.

\begin{tabular}{lllllllllll}
\hline \multicolumn{2}{c}{ Variables } & $\begin{array}{l}\text { Autho- } \\
\text { ritarian }\end{array}$ & Aggressive & Suspicious & Obedient & Selfish & $\begin{array}{c}\text { Deepen- } \\
\text { dent }\end{array}$ & Friendly & $\begin{array}{c}\text { Altruism- } \\
\text { tic }\end{array}$ \\
\hline $\begin{array}{l}\text { Marriage } \\
\text { satisfaction }\end{array}$ & $\begin{array}{l}\text { Spearman`s } \\
\text { rho }\end{array}$ & .000 & -.096 & $-.272^{* *}$ & -.169 & .000 & $-.299^{* *}$ & -.127 & -.126 \\
& $p$ & 1.000 & .345 & .006 & .093 & 1.000 & .003 & .207 & .213 \\
\hline \multirow{2}{*}{$\begin{array}{l}\text { Family } \\
\text { satisfaction }\end{array}$} & $\begin{array}{l}\text { Spearman`s } \\
\text { rho }\end{array}$ & $.251^{*}$ & .125 & .071 & $.228^{*}$ & .114 & .145 & $.276^{* *}$ & $.302^{* *}$ \\
& $p$ & .012 & .217 & .480 & .023 & .259 & .151 & .006 & .002 \\
\hline
\end{tabular}

*. Correlation is significant at the .05 level (2-tailed). ${ }^{*}$. Correlation is significant at the .01 level (2-tailed).

As could be seen from the table above, marriage satisfaction and suspicious interpersonal relationships showed negative and statistically significant correlation and that is to say, as high the level of marriage satisfaction is, as lower the degree of suspiciousness between the partners is $r_{\mathrm{s}}=-.272 ; p=.006$. Almost the same value is viewed from the column about dependent type relationships and the marital satisfaction $r_{\mathrm{s}}=-.299 ; p=.003$, so the link between the two variables is negative and it means as high the level of dependency feeling is, as lower the level of marital satisfaction is.

The same Table 6 gives information about the results between the experienced levels of family satisfaction and the degrees of authoritarian type, obedient, friendly and altruistic types of interpersonal relationships. According to the given in this table information, all four variables with significant correlation with family satisfaction presented positive link and it means that with the growth of one of the variables grows the other one.

The strongest correlation is between the degree of altruism and the level of family satisfaction $r_{\mathrm{s}}=.302 ; p=.002$. The next result with significance is between the experienced level of friendliness as a type of interpersonal relationship and the degree of satisfaction with the family, so the received value here was $r_{\mathrm{s}}=.276 ; p=.006$ that is to say, the friendlier the partners feel each other, the more satisfied they feel with their family. The third demonstrated correlation with significance was between the level of the authoritarian type of interpersonal relationship and family satisfaction $r_{s}=.251 ; p=.012$. On first sight, this result seemed not logical, some explanations could be given here from the family structure point of view. When people think of the family they usually see it as a hierarchical structure where mothers and / or fathers are on the top or are on the first line and children just follow them. Somehow such a structure is needed from the family members and expected from them to have a person that is responsible for the most things happening in the family. The last result obtained with Spearman`s rho was $r_{\mathrm{s}}=.228 ; p=.023$ and it pointed that with the heightening the level of the obedience heightens the degree of family satisfaction. Actually, the reason for getting the last two results are to be found in the folks' deeply-rooted convictions that in the family some members act as the head of the family and the other ones take the subordinate role and obey the rules.

\section{Discussion}

The presented research was intended to explore the connection between the levels of marriage and family satisfaction with different interpersonal relationship types. The main goal of the study was to find out whether there are any statistical significant proofs that the experienced level of marriage and family satisfaction would differentiate according to the authoritarian, egoistic, aggressive, suspicious, submissive, dependent, friendly and altruistic styles of interpersonal relationships. Therefore, it was hypothesized there would be significant differences between the experienced levels of marriage and family satisfaction according to the different interpersonal relationship types. The 
given data for proving first suggestion showed differences between the experienced degree of family and marital satisfaction concerning the types of interpersonal relationships. The result proved the Vol. 13, No. 1, 2019 hypothesis and it was consistent with the works of other authors (Grossman \& Rowat, 1995). This result made it possible to conclude that the experienced level of marital and family satisfaction could differentiate according to the type of interpersonal communication of the examined people with an authoritarian style of communication, revealing themselves in superiority style over other family members. Often those people tend to express their own opinions and desires in a more "bossy" way, they are also prone to occupy a special place in the family group, showing self-satisfaction, narcissism. People with this style of communication, in terms of severity, stubbornness, and hostility as well as people with the obedient type of interpersonal relationship manifest criticism, disappointment, some negativity and alienation from the surrounding world, family and partner, so that they fear of ill-treatment and have low satisfaction with the family. From the other point of view, to have control of a family group is needed to have somebody that could act "bossy", to build and protect the family boundaries and at the same time another part that is important for the family structure is this unite that is prone to obey laws, norms. This could be seen from the results given here, with the increasing of the levels of authoritarian and obedient types of interpersonal relationships, heightens the levels of family satisfaction. According to Olson (2004), family satisfaction is when family members feel happy and satisfied with each other and Gelles (1995) pointed out that the marital satisfaction was determined by the subjective assessment of the overall marriage.

Another suggestion was that there would be correlations between the levels of marital satisfaction and some interpersonal relationships, and between the degrees of family satisfaction and some interpersonal relationships. Consistently to the hypothesis and to all other researches in this area this research question was proven. Some earlier works have revealed connection between family satisfaction and the communication patterns (Akhlaq, et al., 2013; Noller, Fitzpatrick, 1990). In the present study surveyed persons with a friendly style of communication expressed themselves as cooperating others, flexible in solving problems and conflicts, observing the requirements of "good tone" in dealing with family members and, showing warmth and friendliness. The same way of behavior concerns people with an altruistic and obedient style of communication showing a strong sense of responsibility toward family members, delicacy, and kindness, empathy and commitment with their counterparts. The link between family satisfaction and interpersonal communication has been proved by Schrodt, Soliz, and Braithwaite (2008). The correlations here between family satisfaction and the discussed above interpersonal relationships are positive which means the high levels of the mentioned types are related to high family satisfaction. In contrary to the family satisfaction, the correlations between marriage satisfaction and the types of interpersonal relationships showed a significant and negative correlation between the suspiciousness and the dependence from one side and marital satisfaction from another side. That is to say in the marriage any kind of suspiciousness and dependency is not well appreciated, when one of the partners is suspicious that influences the trust between the partners and suffers the quality of their connection. From this point of view, this affects the experience of marriage satisfaction. To have a partner means to rely on the other but not to lose oneself as shown from the given results where marriage satisfaction is low when the feeling dependency is high (negative correlation).

There were taken into account some social-demographic factors that showed no differences between: two genders (male and female), and the partner's status (marital and cohabitating). The differences between the genders are culturally determined (Yakova, 2013) and some explanations are to be found in the theory of social roles (Eagly \& Wood, 2012). In this study the size of the two gender groups is not big enough, so that the examined marital and family satisfactions could be interpreted only as very personal emotional experience but not as gender dependant variables. The number of persons in the studied two groups (married and cohabitating) was also not equal and that makes any discussions about the comparison between the two groups irrelevant.

\section{Conclusions}

The family and coupling have their specific role and place both in the overall social life and in the relationships between family members. The sophisticated relationship between marriage and 
family and the tendencies in their development showed that the type and quality of the interpersonal relationships reflect on the quality of the interaction between partners in the couple.

Communication takes up much of the daily life of the persons, it is an important and valuable part for taking conjoint actions especially in the family and marriage. People's life, thoughts, emotions and experiences are related to and shared with the others. Through an intensive interpersonal relationship, one finds out more about oneself, builds one 's personality, and establishes oneself. This basic need for communication is deeply rooted in human nature and is achieved through intensive interpersonal relationship with all family members. The way people contact and communicate with each other is influential and determinative for the formation of specific interpersonal relationships and for the degree of satisfaction between the partners in the couple and between all family members.

Through love, marriage and family satisfaction one enjoys one's own life because it makes one feel special. Shared positive feelings and kind emotions such as love, warmth, and appreciation are valuable for a satisfying life. Therefore, many people exert efforts to build a family, to have a home and children, to have an intimate relationship, and some of them really struggle to change themselves only to be loved.

A very important novelty of this study is that it showed differences between experienced levels of family and marital satisfaction in regard with the people's interpersonal relationships. In almost all researches about family and marital satisfaction, these two concepts are interpreted as interchangeable. The satisfaction with family is much more related to the happiness experienced in daily life with all family members (parents, children, husbands, wives), while marital satisfaction is about the quality of the partner's relationship (husband-wife). Interpersonal relationships are a major factor in the development of the human being. They are also a condition for the realization of the joint activity among people. The family and marriage remain some of the most influential factors in people's life that shape their interpersonal relationship type. Usually, satisfaction is conceived as a sense of happiness and balance when desires are fulfilled and the family is a fundamental factor for the formation of personality and building up specific interpersonal relationships.

\section{Limitations and Future Implications}

The main limitation as pointed previously is the small and unequal sample regarding the socio-demographic factors. Supported by the literature review it was assumed that the different styles of interpersonal communication will differentiate the levels of family and marital satisfaction and that was asserted in this study but for future work on this topic, it would be more beneficial to use another research instrument for assessing interpersonal relationships with smaller number of variables. Leary`s measurement is not appropriate for small samples because the data get too much distracted upon many factors. In summary, it has been demonstrated that different interpersonal communications and styles serve as markers about the experienced level of satisfaction with the mate but a continuation of researches in that direction is needed to reach a deeper view on the processes in the family.

\section{References}

Akhlaq, A., Malik N. I., \& Khan, N. A. (2013). Family communication and family system as the predictors of family satisfaction in adolescents. Science Journal of Psychology, 1(6). doi: 10.7237/sjpsych/258.

Angelova, N., \& Zaimova-Tsaneva, E. (2018). Balgarska aprobatsia na skala za izmervane na udovletvorenost ot semejstvoto s prilagatelni (F.S.A.S) [Bulgarian approbation of the family satisfaction by adjectives scale (F.S.A.S.)]. Psychological Thought, 11(1), 33-44. doi:10.5964/psyct.v11i1.257

Barraca, J., Yarto, L. L., \& Olea, J. (2000). Psychometric properties of a new Family Life Satisfaction Scale. European Journal of Psychological Assessment, 16(2), 98-106.

Beck, J. S. (1995). Cognitive therapy: Basics and beyond. NewYork: Guilford.

Brazelton, T. B., \& Yogman, M. (1986). Affective development in infancy. Norwood, N.J.: Ablex Pub. Co.

Burgess, E. W., \& Cottrell, L. S. (1939). Predicting success or failure in marriage. New York: Prentice-Hall. 
Couch, C. (1992). Towards a theory of social processes. Symbolic Interactionism, 15, 117-134.

Clark, M. S., \& Reis, H. T. (1988). Interpersonal processes in close relationships. Annual Review of Psychology, $39(1), 609-672$.

Dattilio, F. M. (2001). Cognitive behavior family therapy: Contemporary myths and misconceptions. Contemporary Family Therapy, 23, 3-18.

Duck, S. (1990). Out of the frying pan and into the 1990s. Journal of Social and Personal Relationships, 7(1), 5-28.

Eagly, A., \& Wood, W. (2012). Social role theory. In P. A. Van Lange, A. W. Kruglanski, \& E. T. Higgins (Eds.), Handbook of theories of social psychology: volume 2 (Vol. 2, pp. 458-476). London: SAGE Publications. doi: 10.4135/9781446249222.n49.

Field, A. (2013). Discovering Statistics using SPSS: (And sex and drugs and rock , $n$ ' roll). 4th edn. London: SAGE.

Friedberg, R. (2006). A cognitive-behavioral approach to family therapy. Journal of Contemporary Psychotherapy, (36), 159-165. doi: 10.1007/s10879-006-9020-2.

Gaughan, E. (1995). Family assessment in psycho educational evaluations: Case studies with the Family Adaptability and Cohesion Evaluation Scales. Journal of School Psychology, 33, 7-28.

Georgiou, S. N. (1995). Family dynamics and school achievement in Cyprus. Journal of Child Psychology and Psychiatry, 36, 977-991.

Gohm, C. L., Oishi, S., Darlington, J., \& Diener, E. (1998). Culture, parental conflict, parental marital status, and the subjective well-being of young adults. Journal of Marriage and the Family, 60, 319-334.

Gelles, R. J. (1995). Contemporary family: A sociological view. Thousand Oaks, CA: SAGE Publications Inc.

Grossman, M., \& Rowat, K. M. (1995). Parental relationships, coping strategies, received support, and well-being inadolescents of separated or divorced and married parents. Research in Nursing and Health, 18, 249-261.

House, J. S., Landis, K. R., \& Umberson, D. (2003). Social psychology of health. In P. Salovey \& A. J. Rothman (Eds.), Social relationships and health (pp. 218-226). New York: Psychological Press.

Johnson, M. P. (1991). Commitment to personal relationships. In W. H. Jones \& D. Perlman (Eds.), Advances in personal relationships, 3, (pp. 117-43). London: Jessica Kingsley Publishers.

Jonev, S. (2004). Sotsialna psihologya [Social psychology]. Vol. 5. Sofia: Sofi-R.

Kelley, H. H., (1983). Love and commitment. In Berscheid, E., Christensen, A., Harvey, J. H., Huston, T. L., Levinger, G., McClintock, E., Peplau, L. A., \& Peterson, D. R.. (Eds.), Close relationships, (pp. 265314). New York: Freeman.

Kessler, M. (2015). The importance of commitment in intimate relationships and how to strengthen it. Zurich: University Press.

Krastev, L., \& Yordanova, B. (2017). Detskata gledna totchka za roditelskoto povedenie sled razvoda, [Children's view of parental behavior after divorce] Mezhdunarodna nauchna konferentsiya "Predizvikatelstva i perspektivi pred savremennata psihologia". Sofia, Bulgaria, University Press "Kliment Ohridski".

Leary, T. (1957). Interpersonal diagnosis of personality. A functional theory and methodology for personality evaluation. Retrieved in November 2015, from https://archive.org/stream/interpersonaldia00learrich/ interpersonaldia00learrich_djvu.txt.

Mead, G. (1997). Razum, az I obshtestvo [Mind, self, and society]. Pleven, Bulgaria: EA-Pleven.

Moskowitz, D. S., Suh, E. J., \& Desaulniers, J. (1994). Situational influences on gender differences in agency and communion. Journal of Personality and Social Psychology, 66, 753-761.

Noller, P., \& Fitzpatrick, M. A. (1990). Marital communication in the eighties: A Decade Review. Journal of Marriage and the Family, 52 (4), 832-843.

Obozov, N. (1990). Psihologya mezhdulichnotnijh otnosheniya [Psychology of interpersonal relationships]. Kiev: Libjid.

Olson, D. H., \& DeFrain, J. D. (2000). Marriage and the family diversity and strengths (3rd ed). Mountain View, CA: Mayfield. 
OF PSYCHOLOGY

IN THE $21^{\text {st }}$ CENTURY Vol. 13, No. 1, 2019

Olson, D. H. (2004). Family Satisfaction Scale. Minneapolis, MN, USA: Life Innovations.

Petrova, V. (2016). Avtoreferat: Dinamika na lichnostni osobenosti i nevrotichna simptomatika pri uchenitsi $v$ gorna uchilishtna vyzrast [Dynamics of some personality characteristics and neurotic symptomatic among children in high school]. Dissertational thesis defended by Department of Psychology at SouthWest University Neofit Rilski, Blagoevgrad, Bulgaria.

Ritzer, G. (2011). Sociological theory 8-th edition. New York: Mc Crow Hill-companies.

Satir, V. (2001). Self-Esteem. Berkeley, California: Celestial Arts.

Schrodt, P. (2009). Family strength and satisfaction as functions of family communication environments. Communication Quarterly, 57, 171-186.

Schrodt, P., Soliz, J., \& Braithwaite, D. O. (2008). A social relations model of everyday talk and relational satisfaction in step families. Communication Monographs, 75, 190-217.

Skinner, H., Steinhauer, P., \& Sitarenios, G. (2000). Family Assessment Measure (FAM) and process model of family functioning. Journal of Family Therapy, 22(2), 190-210. doi.org/10.1111/1467-6427.00146.

Świętochowski, W. (2010). Superficial and systemic diagnosis of family. Polish Psychological Bulletin, 41 (3), 113-121. doi: 10.2478/v10059-010-0015-1.

Stamatov, R., \& Minchev, B. (2003). Psihologia na choveka [Psychology of human being]. Plovdiv: Hermes.

Stolin, V. V., Romanova, T. L., \& Butenko, G. P. (1984). Oprosnik udovletvorenosti brakom [Questionnaire for marriage satisfaction]. Vestnik Moskovskogo Universiteta. Seria 14, Psihologia, 2, 54-60.

Stoyanova, S. (2007). Osnovi na psihologicheskite izmervania - adaptatsiya na test [Basis of psychological measurement - test approbation]. Blagoevgrad, Bulgaria, University Press: Neofit Rilski.

Van Lange, P. A., Rusbult, C. E., Drigotas, S. M., Arriaga, X. B., Witcher, B. S., \& Cox, C. L. (1997). Willingness to sacrifice in close relationships. Journal of Personality and Social Psychology, 72(6), 1373-1395.

Veenhoven, R. (1996). The study of life satisfaction. In W. E. Saris, R. Veenhoven, A. C. Scherpenzeel, \& B. Bunting (Eds.), A comparative study of satisfaction with life in Europe 11-48. Budapest, Hungary: Eotvos University Press. Retrieved in May 2019, from https://personal.eur.nl/veenhoven/Pub1990s/96d-full.pdf.

Wayne, D. W. (1990). Spearman rank correlation coefficient. Applied Nonparametric Statistics (2nd ed.). Boston: PWS-Kent. pp. 358-365.

Weissman, M. M., Markowitz, J. C., \& Klerman, G. L. (2000). Comprehensive guide to interpersonal psychotherapy. New York: Basic Books.

Yakova, I., \& Yonkova, N. (2013). Sotsiologia na pola [Sociology of gender]. Blagoevgrad, Bulgaria, University Press "Neofit Rilski".

Yakova, I. (2016). Vavezhdasht kolazh ot sotsiologitcheski distsiplini [Introducing a collage of sociological disciplines]. Blagoevgrad, Bulgaria, University Press: Neofit Rilski.

Received: April 11, 2019

Accepted: June 12, 2019

Natasha Virmozelova Angelova (Corresponding author)
Ph.D., Assistant Professor, Department of Psychology, South-West University "Neofit Rilski", Ivan Mihaylov 66 str., 2700 Blagoevgrad, Bulgaria.

E-mail: natasha.virmozelova@gmail.com 